\title{
Telehealth in the developing world: current status and future prospects
}

This article was published in the following Dove Press journal:

Smart Homecare Technology and TeleHealth

2 February 2015

Number of times this article has been viewed

\author{
Richard E Scott ${ }^{1,2}$ \\ Maurice Mars' \\ 'Department of TeleHealth, \\ University of KwaZulu-Natal, Durban, \\ KwaZulu-Natal, South Africa; ${ }^{2} \mathrm{NT}$ \\ Consulting - Global e-Health Inc., \\ Calgary, AB, Canada
}

Abstract: In a setting of constant change and confusing terminology, telehealth continues to gain ground in both developed and developing countries within the overarching milieu of e-health. Evidence shows telehealth has been used in essentially all countries of the world, but is embedded in few. Uses and needs of telehealth vary between the developed and developing world; the latter struggles with both communicable diseases and noncommunicable diseases, and with very few resources. Common clinical applications include teleconsultation, telecardiology (transmission of ECGs), teleradiology, and teledermatology. Many telehealth projects exist throughout Latin America and the Caribbean, Asia, and Africa, but there is little published evidence and only isolated examples of sustained programs, although several sustained humanitarian networks exist. Application of mobile solutions (m-health) is on the rise in many developing countries. Telehealth is still not integrated into existing health care systems globally. Reasons vary: lack of proven large-scale operations, poor evidence base, inadequate implementation, lack of attention to the "soft side" of implementation (readiness, change management), and many others. For the developing world, reasons can be more pragmatic, including limited resources, unreliable power, poor connectivity, and high cost for the poverty stricken - those most in need. Telehealth is poised to improve health and health care in the developing world, driven by both altruistic and profit motives. But to have the desired effect, telehealth must address very specific and evidence-based health "needs" of each facility, region, or country; the shortage of health workers and specialist services; and the required skills upgrading and training, allowing the developing world to establish its own critical mass of experts. This will only be achieved by raising awareness, understanding, and ability regarding telehealth capability and limitations, and by the coordinated political and professional will of all those involved to guide public and private innovation and telehealth integration.

Keywords: telehealth, telemedicine, developing countries, e-health, review

\section{Introduction}

Health and well-being are complex matters. At the individual level, health care services, wellness, and behavior all impact health and well-being, but at the population level so too do social and economic policies and politics. The link between "economic well-being" and "health/well-being" is accepted. Countries differ substantially in their levels of health and well-being, but in general terms those countries with higher wellbeing are those that are more economically developed with higher personal income leading to better health.

Increasingly, the link between use of information and communications technology (ICT) and the future of health and health care is acknowledged, if not broadly
Correspondence: Richard E Scott NT Consulting - Global e-Health Inc., 703, 1540-29th Street NW, Calgary, $\mathrm{AB}$, Canada T2N 4MI

Tel +l 4038702070

Email ntc.ehealthconsulting@gmail.com 
accepted or integrated. Use of ICT in health is termed e-health. ${ }^{1}$ The first significant and systematic use of e-health was primarily for military and space applications, but its use has steadily broadened. Bringing any innovation to maturity is a challenge, yet this seems inexplicably so for e-health, particularly telehealth, which, in various guises, has been "in development" for well over 100 years. ${ }^{2}$ Indeed, the first use of "ICT for health" may have been in the 1860 s when telegraph messages were sent to seek help for treating wounded soldiers during the American Civil War - nearly 155 years ago. ${ }^{3}$

Arguably e-health comprises four main elements:

- e-commerce (the business side)

- e-learning (the training - awareness, teaching, instruction, and education - side)

- Health informatics (the data gathering, storage, analysis, and distribution side)

- Telehealth (the interactive - real-time or store-andforward - side).

Investment in innovative e-health research, followed by adoption and integration of proven e-health solutions, is becoming a key aspect of sustainable economic development and health system restructuring, particularly for the developing world. ${ }^{4}$ Yet a primary issue remains - what e-health solutions should be invested in?

The focus of this paper is on one element of e-health telehealth. However, any technologically appropriate and culturally sensitive solution ${ }^{5}$ based on health "need" may, in fact, require different proportions of all four elements. In general, speaking of "e-health" solutions is more appropriate than speaking of telehealth, health informatics, e-learning, or e-commerce as individual solutions. e-Health is often used in this paper as the overarching term, with specific reference to individual elements (especially telehealth, and m-health) as and when more focus is necessary. Definitions - and misuse of terms - abound. ${ }^{6}$ A generic definition for the element of telehealth is used here. Telehealth is the use of ICTs to exchange health information and provide health care services across geographic, time, social, cultural, and political barriers.

Telehealth encompasses activities often termed telemedicine, telecare, or telehomecare, among others. Regardless of the term used, it is important to understand the breadth of technology, application, and role of telehealth. For example, telehealth:

a. uses any form of ICT device (from a desktop PC, through laptops and i-pads, to smart devices and sensors);

b. covers preventative, promotive, and curative aspects of health; c. uses simple or complex multimedia to videoconferencing to virtual reality;

d. can be interactive (synchronous - "real-time" personto-person or person-to-software engagement; or asynchronous - delayed messaging such as e-mail);

e. engages and links all types of users (from highly trained clinicians to minimally trained community health care workers (CHWs), to patients, to the general population); and

f. can be used as an alternate or complementary approach for almost any health issue imaginable.

The further focus of the paper is on the "developing world". There is no established convention for the designation of "developed" or "developing" countries in the United Nations system, and although countries emerging from the former Yugoslavia might be considered developing countries, those of Eastern Europe and the former USSR are not generally included under either developed or developing designations. This chapter therefore examines "developing" countries in the Latin American and Caribbean (LAC), Asian, and African regions.

A recent search of PubMed, a bibliographic database of medical research that is maintained by the National Library of Medicine, returned 18,252 results for the search term "telehealth" alone. Significant research has been performed, but more is required as the quality of research and value of the resulting solutions have been frequently questioned, particularly for economic studies. ${ }^{7-11}$ However, the sheer volume and generally positive impact of the telehealth literature must hold some weight. The need for a "realistic review" to explain what works, for whom, and in what circumstances seems urgent. ${ }^{12,13}$ Regardless, at this time, telehealth has still not reached the critical tipping point either globally or in the developing world.

One reason may be the tendency in the developed world to focus attention on clever, narrow, or "one-disease" applications (eg, telediabetes; telesurgery). Yet patients typically do not have "one disease", and few of the World's seven billion plus population will need or benefit from telesurgery. Solutions for the developing world must be more pragmatic. They must not be attempts at emulation of developed-world solutions, but must address the specific needs and contexts of the developing world.

Many articles speak of the "potential" of telehealth, especially for providing access to care for individuals in rural and remote locations. This potential must be converted to reality for the developing world, which struggles with inhumane circumstances. Nowhere is this more evident 
than in Africa. This continent is home to $14 \%$ of the World's population, and still struggles with $24 \%$ of the global burden of disease (GBD), and yet is served by just $3 \%$ of the world's health workers with access to merely $1 \%$ of world health expenditure. ${ }^{14}$ The issue is global; the World Health Organization (WHO) identified five developing countries in LAC, 12 in Asia, and 39 in Africa facing severe shortages of health workers. ${ }^{14}$ The Organization for Economic Cooperation and Development has an average of 320 doctors per 100,000 people, although ironically the link between the national per capita number of doctors and health care outcomes is debated. ${ }^{15,16}$ However, the human health resource situation in Africa is desperate, with the average for the WHO Africa Region being just 26 physicians per 100,000 people. $^{17}$ Cooke et $\mathrm{al}^{18}$ note the skewed distribution between urban and rural areas that worsens such estimates, stating that in South Africa $\sim 43 \%$ of the population who live in rural areas have available just one general physician to every 7,700 peopleabout 13 physicians per 100,000. In addition, Chanda and Shaw ${ }^{19}$ describe in Zambia a health sector operating at $50 \%$ of its intended complement, and with almost $45 \%$ of rural health centers being run by unqualified health workers. They indicate that some provinces operate at a doctor-topopulation ratio of $1: 69,000$ - the ratio recommended by the WHO is 1:5,000. This renders such health systems all but incapable of providing even basic health care services to their population.

Telehealth is considered by some an appropriate response to such dire circumstances and if devised and implemented correctly could ameliorate this situation. ${ }^{20}$ The developed and developing world are often assumed to have similar heath issues, but the need and perspective differ. Similarities do exist, eg, the burden of noncommunicable diseases (the leading causes of death worldwide, particularly premature death), and aspects related to distance and maldistribution of health care providers. Here the WHO has pointed to education as being a primary leverage point ("There is strong evidence for the correlation between a host of social determinants, especially education, and prevalent levels of NCDs and risk factors"). ${ }^{21}$ But there are differences also, such as high cost, underdeveloped infrastructure, and lack of technical expertise. Table 1 shows some of the primary issues from a developing world perspective, based on the authors' experience. Given these disparities, the optimal solutions required to address the issues and needs - including telehealth options - will also differ.

Addressing this reality will involve focused delivery of technologically appropriate and culturally sensitive solutions
Table I Health issues and needs of the developing world

\begin{tabular}{|c|c|}
\hline Age & $\begin{array}{l}\text { Although also experiencing an "aging } \\
\text { population" phenomenon, developing } \\
\text { countries still see a youthful demographic } \\
\text { (some African countries have a median age } \\
\text { of just I } 5 \text { years) }\end{array}$ \\
\hline Poverty & $\begin{array}{l}\text { Despite MDG progress, the extreme poor } \\
\text { (one in five people in developing regions) } \\
\text { still live on less than } \$ 1.25 \text { per day }\end{array}$ \\
\hline Communicable diseases & HIVIAIDS, TB, and malaria remain prevalent \\
\hline Maternal and child health & $\begin{array}{l}\text { Despite MDG progress, mortality remains } \\
\text { unacceptably high in many locations }\end{array}$ \\
\hline Violence and conflict & $\begin{array}{l}\text { Interpersonal violence and conflict are } \\
\text { greatest in the developing world }\end{array}$ \\
\hline Workforce shortages & $\begin{array}{l}\text { Number, skill level, and focus (expertise in } \\
\text { health; e-health; technical support) remain } \\
\text { critically low }\end{array}$ \\
\hline Critical mass & $\begin{array}{l}\text { Inability to "build the capacity to build } \\
\text { capacity" }\end{array}$ \\
\hline $\begin{array}{l}\text { Poor district health } \\
\text { systems }\end{array}$ & $\begin{array}{l}\text { Understaffed and underresourced, } \\
\text { particularly rural and remote locations }\end{array}$ \\
\hline $\begin{array}{l}\text { Poor district health } \\
\text { information systems }\end{array}$ & $\begin{array}{l}\text { Inadequate data collection and analysis } \\
\text { capability; long delays if paper-based }\end{array}$ \\
\hline Access & $\begin{array}{l}\text { Limited availability of broadband Internet } \\
\text { and other network communication systems }\end{array}$ \\
\hline Cost & $\begin{array}{l}\text { High communication costs (infrastructure } \\
\text { and usage fees) }\end{array}$ \\
\hline Literacy & $\begin{array}{l}\text { Educational and technological literacy } \\
\text { remain low }\end{array}$ \\
\hline Language & $\begin{array}{l}\text { Differences in languages spoken by remote } \\
\text { health care providers and local patients } \\
\text { prevalent; local languages may lack words } \\
\text { to express certain meaning or activity }\end{array}$ \\
\hline Political support & $\begin{array}{l}\text { Unrealistic expectations and poor } \\
\text { understanding squander political will and } \\
\text { commitment to sustainable telehealth }\end{array}$ \\
\hline Power (electricity) & Inadequate access and unstable supply \\
\hline
\end{tabular}

Abbreviations: MDG, Millennium Development Goals; TB, tuberculosis.

that align with "glocal" (global and local) health system and health "needs" of each entity (institution, subnational region, country) and culture involved, ideally in the form of an evidence-based, needs-based, transparent, and defensible strategy. ${ }^{5,22}$ In this way, telehealth could provide greater access to broader health expertise through teleconsultations, raise the skills and knowledge of local health care providers through training, and even foster greater self-care and wellness habits of a population through awareness building and behavioral change. Although not the entire solution, it could help considerably.

The developed world has a vested interest in improved global health and developing world solutions. More and more, diseases are becoming a global concern. Neglected, or orphan, diseases - once considered a scourge of just the developing world - are now able to spread rapidly and globally. The very porous nature of our formerly restrictive political 
borders and rapid transportation to anywhere in the world has changed this. This reality was demonstrated through the HIV/AIDS and SARS pandemics, and even the current rise in global concern around Ebola. We can no longer focus on issues - or technological solutions - as if they were solely of sovereign concern, but must now also consider the global implications of what we do locally (ie, "glocal" e-health). In addition, the resource limitations of most developing country settings will require telehealth (indeed, e-health) solutions to be not just effective, but simple and inexpensive (ie, technologically appropriate). The developed world can benefit from such developing world innovation; this flow is "reverse" to the traditional aid-driven flow and has been coined "reverse innovation".

But the driving force is far from altruistic. Telehealth represents big business. The global telehome and telemedicine market reached $\$ 13.8$ billion in 2012 , and this market is expected to grow to $\$ 35.1$ billion by $2018 .^{23}$ Similarly the global m-health market is expected to hit $\$ 21.5$ billion in 4 years, with an annual growth rate of $\sim 55 \%$, and the global remote patient monitoring market (comprising external monitoring devices and implantable monitoring devices) is believed to be primed for significant growth. ${ }^{24,25}$ Most of this will be in developed countries initially (Europe and North America), but even developing countries remain a business opportunity - someone (an individual, insurance company, or government) has to pay for health care, whether facilitated by e-health or not. More significantly, the world's top economies are shifting, and People's Republic of China, India, and Brazil are expected to move higher, and Mexico to enter, the top 10 economies by 2020 . Huge populations, rising household incomes, and younger consumers may stimulate public interest in e-health. What might be the return on investment for the developing world, and for whom - the state or individuals? Significant claims have been made of cost savings in the developed world, but such savings are unlikely to accrue to most of the developing world. ${ }^{22,26}$ There must be other benefits - other "value" - identified and respected.

There is an air of inevitability associated with the use of "e-health" (including telehealth) for future health care and wellness support in developing countries. But the key will be to invest wisely in the identification, demonstration, and implementation of only solutions proven to offer broad value in those settings. This will require judicious application of lessons learnt from current use, astute understanding of barriers and options to overcome them, and imaginative and innovative application of technologically appropriate solutions.
After describing the breadth of current use of telehealth in developing countries, this review describes some general challenges and concludes by considering future prospects for telehealth in the developing world.

\section{Current use}

When compared to that for developed countries, relatively little published evidence exists of the extensive telehealth work known to occur in developing countries. e-Health-related activity has taken place within the last 15 years in all but $31(13 \%)$ of the world's 238 United Nations-recognized countries. ${ }^{27}$ Some reviews of e-health (including telehealth) exist, and many books and reports (gray literature) are available demonstrating the spectrum of telehealth in developing countries. ${ }^{28-32}$

Asia, the most populous continent, is home to about 4.3 billion people ( $\sim 60 \%$ of the global population) and includes the world's two most populated countries - People's Republic of China and India - which together constitute about $37 \%$ of the world's population. Africa, the second most populated continent, has about 1 billion people $(\sim 15 \%$ of global population), while the LAC regions are home to around 600 million ( $~ 9 \%$ of global population). Most "developing countries" are in these regions and constitute about $80 \%$ of the global population.

Lewis et $\mathrm{al}^{33}$ showed that various types of ICT are being used by private organizations in low- and middle-income countries to address key health system challenges. Specifically, the main challenges identified were increased access (42\%), data management (38\%), virtual patient-provider communication (31\%), improved diagnosis and treatment (17\%), mitigating fraud and abuse (8\%), and streamlined financial transactions (4\%). The most commonly used devices were phones (71\%) and computers (39\%). They also identified that donors are the primary funders of almost half of e-health programs (47\%).

Telehealth (or telemedicine) has been used in response to conflict-based or disaster-based humanitarian need. ${ }^{34,35}$ Beyond this, activity can be seen in many developing countries; for example, Brazil, Cambodia, Ecuador, India, Nepal, Philippines, and South Africa, among others. ${ }^{32}$ In Asia, recent growth in application of telehealth has been seen in both India and People's Republic of China, with continued growth expected in the coming decade. Many countries in Africa also exhibit activity. In LAC countries, a tremendous level of activity can be seen in Brazil, where telehealth has become embedded in the delivery of health care. ${ }^{36,37}$

Although most initiatives remain locally focused and at the pilot or project stage, sustained telehealth networks also 
exist, providing humanitarian telehealth internationally. The networks typically provide support for educational or clinical purposes and adopt one of two models for clinical referrals (targeted model and open/distributed model). ${ }^{38}$ Humanitarian telehealth networks include

- Réseau en Afrique Francophone pour la Télémédecine (RAFT) Network

- PAN African e-Network

- Swinfen Charitable Trust

- Africa Teledermatology Project

- Institute of Tropical Medicine (TM) Telemedicine

- Pacific Island Health Care (PIHC) Project

- Partners Online Specialty Consultations

- Balkans e-Health Network

- Teletrauma.

Wootton et $\mathrm{al}^{39}$ described seven of nine long-running networks (operating for 5-11 years). These networks provided clinical tele-consultations using store-and-forward methods; four address all clinical specialties with the remainder being more specialized. One used videoconferencing for trauma cases, and five also provided educational activities. ${ }^{39}$ Between 2006 and 2011, three showed a positive trend in network activity, three a negative trend, and one stable activity; on average, network activity increased by about $10 \%$ each year. Mars and $\mathrm{Scott}^{40}$ introduced a metric as a standard measure of network usage (consultations per site per week [C/S/W]) and showed that this number invariably lies below 2, which they considered unacceptably low and raised concern about how well current clinical services are used.

Wootton et $\mathrm{al}^{39}$ concluded the strength of the evidence was generally poor by conventional standards (eg, 29 papers described noncontrolled clinical series), although most papers provided some evidence of sustainability and improved access to care. A common risk factor was uncertain funding. The University of KwaZulu Natal, Durban, South Africa has been using ICT-facilitated teaching for over a decade, simultaneously broadcasting (and recording) lectures to four University of KwaZulu Natal campuses locally. They also teach graduate telehealth and informatics degree programs throughout sub-Saharan Africa using various video-based software programs (eg, Scopia) and Learning Management Systems (eg, Moodle), and even simply record and distribute $\mathrm{CD} / \mathrm{DVD}$ lectures for continuing education. ${ }^{41}$

\section{Telehealth in LAC}

In this region, application of e-health has grown significantly. ${ }^{42}$ Brazil has applied telehealth most comprehensively. Brazil is a huge and complex country with a population of
201.4 million distributed unevenly among 26 states and one federal district. The country has invested heavily in applying telehealth to enhance its municipality-based primary care system through Telehealth Units located in urban, rural, and remote basic health centers. It aligned three national networks to create a pilot project which, with strong leadership and political support, matured and transitioned into a national program. The program now supports service (teleconsultation in many clinical fields; formative second opinion), education (in-service and higher education), and research.

Minas Gerais, a state in the south of Brazil, exemplifies the application of telehealth for its 19 million residents in 853 municipalities. ${ }^{35}$ In 2005, the state government established a small-scale telehealth network focusing on cardiology that connected five public university teaching hospitals with 82 municipal health departments serving 10,500 inhabitants. By 2012 the network was embedded in the primary health care system of over 300 municipalities and served about $47 \%$ of the state's population, performing on average 1,450 teleelectrocardiograms as well as 77 teleconsultations each day. An element of success is related to the use of inexpensive equipment, but a limitation is restriction of teleconsultations to physicians only (Brazil's Board of Physicians does not authorize teleconsultations between physicians and patients). Minas Gerais reportedly invested about \$9 million USD and estimated a cost savings over a period 5 years of \$20.08 million USD (a cost-benefit ratio of $\sim 2.24: 1$ ).

\section{Telehealth in Asia}

This region is home to a great number of countries diverse in their level of economic development and application of telehealth. No recent review of telehealth in Asia was found. Durrani and Khoja performed a systematic review of telehealth in Asia in 2009. ${ }^{30}$ They found most studies were from Japan (37\%), and the most common modes of application were store-and-forward (43\%), videoconferencing (35\%), or a hybrid approach (15\%). Studies were primarily descriptive $(75 \%)$, with only eight including comparison against a control group.

The region is one of profound heterogeneity in terms of relative wealth and use of technology (with Malaysia and Singapore at one extreme, and perhaps Vietnam and Cambodia at the other) and population (with the most populace countries being India and People's Republic of China). Malaysia took bold steps as long ago as 1996, declaring various telehealth-related laws and implementing a "Multi-Media Supercorridor" initiative, and introducing a Lifetime Health Plan with a "lifelong PHR" for every 
citizen (which proved unsustainable). ${ }^{43,44}$ India's government is reported to have planned and implemented national-level telehealth projects in an attempt to overcome its inability to provide accessible and quality health care to much of the country, with the Apollo Hospital Group having been very successful with employing telehealth, but the country is struggling to achieve scale and sustainability. ${ }^{45-47}$ Sharma $^{45}$ also noted that India had developed telehealth services and education in South Asian and African countries. Post SARS, People's Republic of China also has begun to employ e-health more systematically. ${ }^{48,49}$ Scanning the literature reveals that many other developing countries in the region use telehealth to varying degrees, for various purposes, and with varying success, but mostly in the context of projects; there is little evidence of sustained application of programs and poor publication for any single country or the region as a whole.

\section{Telehealth in Africa}

Currently, the focus of e-health in Africa is reported to be toward telehealth, health education, and health-related research, with the number of $m$-health projects rising rapidly in recent years. ${ }^{28}$ A recent study showed that there were $51 \mathrm{~m}$-health programs that were being operated in 26 developing countries. Funding for these activities came from a wide range of funding bodies, some of which had specific geographic focus. Not all interventions are promising, but increasingly many African countries see e-health interventions increasing in number, particularly those with higher Gross National Income. ${ }^{50}$ Although no recent review was found, Mars recently summarized telehealth in Africa. ${ }^{51}$ He identified significant clinical activity in telecardiology, teleradiology, telepathology, teledermatology, teleobstetrics, telepsychiatry, and teleophthalmology, as well as tele-education, with more localized and trial or project activities in many areas (promoting HIV testing; appointment reminders, medication adherence, family planning, teleorthopedics).

\section{$\mathrm{m}$-Health in the developing world}

Cell phones have rapidly evolved in the last 2 decades giving rise to "smartphones" and other smart devices (ie, sensor-rich and Internet-enabled). Today even "basic" devices have significant multimedia capability that can be explored to build powerful tools (eg, for surveillance or learning). With the advent of "m-health" (simply e-health using mobile devices) and availability of smartphones, the developing world has seen a plethora of initiatives, many directed toward the support of rural and isolated CHWs and child and maternal health needs. ${ }^{52-56}$ Piette et al ${ }^{57}$ reported that automated telephone monitoring and self-care support calls have been shown to improve some outcomes for chronic disease management, such as glycemia and blood pressure control, in low- and middle-income countries, and Gozzer ${ }^{58}$ has shown activity in LAC. Sustained m-health projects exist, such as Mobile Alliance for Maternal Action (http://www. mobilemamaalliance.org/), which sends health messages to new and expectant mothers in developing countries via their mobile phones. Mobile Alliance for Maternal Action focuses its efforts on countries where high maternal and newborn mortality rates intersect with a proliferation of mobile phones, and currently is active in Bangladesh, South Africa, and India. Table 2 shows the number of $m$-health initiatives taking place in selected developing countries, as reported by the GSMA m-Health Tracker (a collation of planned and deployed mobile health products and services around the globe; http://www.mobileworldlive.com/mhealth-tracker). Countries were selected to span geographic size, population,

Table 2 Number of $m$-health initiatives taking place in selected developing countries (GSMA m-Health Tracker; August 20I4)

\begin{tabular}{|c|c|}
\hline \multicolumn{2}{|l|}{ Latin America and Caribbean } \\
\hline Argentina & 4 \\
\hline Belize & I \\
\hline Brazil & II \\
\hline Chile & 2 \\
\hline Colombia & 6 \\
\hline Haiti & 4 \\
\hline Peru & 12 \\
\hline Venezuela & 2 \\
\hline \multicolumn{2}{|l|}{ Asia } \\
\hline Afghanistan & 6 \\
\hline People's Republic of China & 15 \\
\hline India & 66 \\
\hline Indonesia & 9 \\
\hline Malaysia & 2 \\
\hline Mongolia & 0 \\
\hline Pakistan & 12 \\
\hline Philippines & 14 \\
\hline Singapore & I \\
\hline Thailand & 7 \\
\hline Vietnam & 6 \\
\hline \multicolumn{2}{|l|}{ Africa } \\
\hline Cameroon & 2 \\
\hline Botswana & 13 \\
\hline Cameroon & 2 \\
\hline Chad & I \\
\hline Ethiopia & 9 \\
\hline Kenya & 44 \\
\hline Nigeria & 34 \\
\hline Rwanda & 6 \\
\hline South Africa & 96 \\
\hline Tanzania & 30 \\
\hline Uganda & 2 \\
\hline
\end{tabular}

Abbreviation: GSMA, Groupe Speciale Mobile Association. 
and economy (GDP). No relationship between activity and these parameters was apparent, suggesting that initiatives remain opportunistic.

\section{Challenges}

Many challenges exist. Here only a few select challenges are highlighted as major stumbling blocks, with opportunities or suggestions for solutions proffered. The challenges presented extend across social, political, and technological domains.

\section{Health human resources}

The 2006 World Health Report, "Working Together for Health", estimated a shortfall of 4.3 million skilled, motivated, and supported health workers worldwide, with 57 countries having insufficient numbers to provide even basic health services. ${ }^{14}$ This reality continues with extreme shortages not only in health care professionals but also in professionals trained and skilled in telehealth and other aspects of e-health. Telehealth can be used to provide and target the various levels of training required. ${ }^{59}$

\section{Population demographics}

The general trend toward increasingly older populations has been occurring for at least 50 years and is occurring in the developing world also. In Asia the next 20 years will see almost a quarter of the region's population needing "elder care", and although the trend is slower in Africa and LAC, still a proportionately larger number of elderly will require care. This will place still further strain on existing health care systems. Greater focus on telehealth solutions that ameliorate this strain are needed.

\section{Awareness and expectation}

Politicians and others have significantly different, and often inaccurate, understanding of what constitutes e-health and telehealth. A common foundation of knowledge and understanding must be developed, and the available technology then used to raise awareness of users and decision-makers, and to provide training opportunities..$^{59,60}$

\section{Double burden of disease}

The developing world continues to face the burden of communicable diseases, but now also must combat a significant rise in the prevalence of noncommunicable diseases. These must be tackled in a resource-scarce setting, without detracting from existing health care system-related efforts to provide basic services. Technologically appropriate and culturally sensitive solutions are required. ${ }^{5}$

\section{Poverty}

Despite achieving the Millennium Development Goal of halving "extreme poverty" from its 1990 level, significant poverty still exists in all parts of the world, and levels are not uniform across all countries or regions. In 2010, just five countries were home to about two-thirds of the world's 1.2 billion “extreme poor”: India (33\%), People's Republic of China (13\%), Nigeria (9\%), Bangladesh (5\%), and the Democratic Republic of the Congo (5\%). ${ }^{61}$ Low-income countries contain most of the "extremely poor" in the world (29\% in 2010). Asia, which is particularly heterogeneous, and the LAC region, each have about $20 \%$ of the world's poor. Sub-Saharan Africa remains the region with the highest proportion of poor, where $48 \%$ of people live on less than $\$ 1.25$ a day. ${ }^{61}$ Telehealth solutions that focus on evidence-based health "need", including social determinants of health, are more likely to address the extremely poor and poor. ${ }^{21}$

\section{Technology and communications availability}

As technology advances, there is an assumption of ubiquity that those in the developing world will have ready access to both affordable wireless communication and feature-rich mobile technology. The International Telecommunications Union figures show that only $31 \%$ of the developing world population is online - just $16 \%$ in Africa $(77 \%$ in the developed world), and $90 \%$ of households not connected to the Internet are in the developing world. ${ }^{62}$ Even for those with technology and access, poor general and technological literacy means use is limited; can a slum dweller (or even a CHW) from a developing country really be expected to own and possess a feature-rich mobile device and sufficient skill and airtime to take and share photographs, record video, receive and comprehend multimedia, or connect to the Internet? In 2014, Jack and Mars ${ }^{63}$ showed that in rural and remote areas of South Africa, many owners were reticent to use their basic cell phones because of the (still) high cost, with $38 \%$ unable to afford airtime for more than 1 week in the past year. For vulnerable groups and those who are extremely poor and poor - those most in need - the reality is much less than the published figures of ICT penetration would suggest.

\section{Health system challenges}

Telehealth is being asked to merge with existing health care systems - akin to fitting a square peg into a round hole when, in fact, it may function best in an entirely new system. Wholesale change of health care systems will not occur, with many still struggling with ongoing reforms to shift toward 
a primary care orientation and universal health coverage. Therefore, the challenge becomes how can health care systems, programs, and policies be adequately adjusted, modified, or otherwise improved to accommodate telehealth? Human nature dictates that if we do not believe in something, we do not put in the effort to make it work. Awareness and knowledge of key stakeholders must be raised, so they think more positively and correctly about the appropriate use and value of telehealth.

\section{Focusing on true health needs}

Recently, the Institute for Health Metrics and Evaluation completed and published results of their GBD 2010 study, and currently their 2013 study ${ }^{64}$ The GBD can be represented by disability-adjusted life years, and these can help to identify glocal health needs. The top health needs of each country (perhaps even subnational region) differ, and this situation is dynamic with changes over time being visible (creating the need for flexible solutions).

As an example, the GBD study also presents risk factors for each country (Table 3). ${ }^{65,66}$ These represent potentially modifiable causes of disease and injury. Might these be good candidates for telehealth interventions that focus on behavioral modification? Table 3 shows that for more than half of the countries studied, the primary risk factor was "dietary risks". This includes components such as high sodium intake and lack of fruit, nuts, and seeds and whole-grain intake. GBD 2010 found that the diseases linked to poor diets and physical inactivity were primarily cardiovascular diseases as well as cancer and diabetes. How can telehealth help? How many current telehealth interventions address such root-cause issues in a coordinated and focused manner?

\section{Level of evidence}

Strong evidence of the impact of telehealth anywhere in the world is lacking. ${ }^{39}$ The context in the developing world

Table 3 The primary risk factor that accounts for the most disease burden in 187 countries studied in the GBD study 2010

\begin{tabular}{ll}
\hline Primary risk factor & Number of countries \\
\hline Dietary risks & $101(53 \%)$ \\
Childhood underweight & $31(17 \%)$ \\
High body mass index & $19(10 \%)$ \\
Household air pollution from solid fuels & $12(6 \%)$ \\
Alcohol use & $8(4 \%)$ \\
High blood pressure & $6(3 \%)$ \\
Tobacco smoking & $5(3 \%)$ \\
High fasting plasma glucose & $3(2 \%)$ \\
Suboptimal breast-feeding & $2(2 \%)$ \\
\hline
\end{tabular}

Abbreviation: GBD, Global Burden of Disease. is known to be different, and those differences may allow telehealth to function better and be more acceptable. Is it necessary to repeat all the research completed in the developed world to show its value in a developing world setting? Some have argued "no". ${ }^{67}$ Traditional, large, multisite trials are expensive and can take years to produce information. Investment in such studies should be carefully weighed against the funding of larger numbers of smaller and innovative (albeit less definitive) studies of solutions adapted to different cultures and settings. ${ }^{57}$ Regardless, it will be necessary to perform adequate research to demonstrate utility and economic viability and to publish that evidence in accessible outlets (open-access journals, without prohibitive processing fees) for the benefit of others.

\section{The softer side}

No matter how good a telehealth solution may be, unless the setting is willing to embrace it, it will not function well - or perhaps at all - if resistance is high. The areas of "readiness" or "preparedness" are important to address prior to any intervention, as is "change management", which must be considered at all stages of the life cycle of a telehealth intervention. Specific actions are necessary to mitigate these challenges, but raising knowledge and awareness of telehealth helps reduce their impact.

\section{Future prospects}

What may the future hold for telehealth in the developing world? This question depends on primary driving forces and can be answered in several ways. Two possible approaches will be considered here: broader aspects or speculation on individual areas of growth.

\section{Broader aspects}

Three broader considerations for the primary driving force in moving telehealth forward in the developing world are 1) technological imperative, 2) status quo, and 3) evidence-based health need.

1. Technological imperative. Strongly influenced by current or anticipated opportunities of profit, big business can continue to be a primary driving force. This leads to seeking problems that the available and developing "cutting-edge" e-health applications may be able to resolve. However, just because something can be done does not mean it should be done; further, vendor answers may not be the needed solutions. By definition, technology and private-sector investment cannot be separated from e-health, but instead of looking toward areas where 
a profit can be seen, industry must be realigned to seek solutions for those areas where evidence shows the greatest need of a country, region, or facility. Profit will follow.

2. Status quo. Political desire to demonstrate advancement, and the fractured understanding of e-health, can continue to conspire and lead investment toward data-based and ad hoc telehealth and e-learning solutions. Practice from elsewhere is often emulated or adapted, or a "Champion" may be leveraged (who will typically focus on initiatives within their area of expertise or practice). This may not be the best use of already limited resources (time, effort, and funding) because any e-health solution represents an opportunity cost. Relevance and sustainability is more likely when solutions address a clear need and are designed and established organically within the context and setting in which they will be applied.

3. Evidence-based health need. What disease or health issue should be resolved? The tendency for governments to "maximize current investment", "build on" existing initiatives, or to seek "low-hanging fruit" is a concern, as these initiatives have typically been identified through "technological imperative" or "status quo" insight. So too is the tendency to have outside agencies (nongovernmental organizations, foreign governments, and religious groups) fund research and implementation of telehealth projects, as they are duty bound to address their own agenda and not necessarily that of the entity concerned. If interests do not align, then these activities can, at the least, become an unwanted distraction or, at worst, a drain on already limited resources. In contrast, having an evidence-informed, needs-based, and defensible e-health strategy in place allows countries, regions, and facilities to be the architects of their own e-health destiny. When a funder, nongovernmental organization, or religious group suggests an initiative, it can be welcomed if it aligns with the established e-health strategy or politely declined if it does not.

The 2010 post-earthquake situation in Haiti was an example of well-intentioned but uncoordinated support. Hundreds of large and small nongovernmental organizations, private-sector groups, and religious organizations, as well as foreign government-led initiatives, arrived and independently engaged in their own focused activity (often unwittingly employing e-health solutions). Very often this was without any knowledge, coordination, or approval of the struggling government (Personal experience of an author [RES]). A subsequently initiated "mandatory" registration process proved impossible to enforce. This example speaks to the need for countries, subnational health regions, and even health care facilities to have their own e-health strategy developed, in place, and enforced. ${ }^{40}$

\section{Speculation on individual areas of growth}

Alternatively, it is possible to speculate on individual areas of growth as future drivers of telehealth in the developing world. Promising areas include $\mathrm{m}$-health, remote monitoring, “apps", games, and training. These are briefly described.

\section{m-Health}

Proven interventions can improve population and individual health only if they reach those who need them. Telehealth has global outreach potential, and m-health innovations seem to be one field of technology application that promise this breadth of impact. m-Health is not a new technology, but simply an inevitable evolutionary occurrence as "wireless" capability expanded, allowing greater access to and use of mobile devices of various kinds. It is finding application in all components of e-health (telehealth, health informatics, e-learning, and e-commerce). Motamarri et $\mathrm{al}^{68}$ gave some insight as to why m-health may become the technological approach of choice for developing countries based upon their experience in Bangladesh. They note $\mathrm{m}$-health's potential for ubiquity and potential to serve the underserved, and its recognition as a scalable and dependable health care delivery platform.

But m-health may not be the silver bullet some believe. Application of m-health to vulnerable groups - ie, those truly in need - may be less immediate, requiring practical and more esoteric mobile device-related issues to be addressed. While growth in rates of data transfer and signal quality continue (eg, $2 \mathrm{G}$ to $3 \mathrm{G}$ to $4 \mathrm{G}$ ), vulnerable groups in poor and rural areas are left without such connectivity due to an unviable business case. Furthermore, a fundamental concern is the exaggeration of the penetration of mobile phones, which are often said to be "ubiquitous" or shown as percentages greater than $100 \%$, erroneously implying that vulnerable groups will have significant ownership, ready access, and ability. ${ }^{63,69,70}$ One study showed severe restrictions in use in rural and remote areas, with nearly $40 \%$ unable to afford airtime for more than 1 week in the past year. ${ }^{63}$ The same study showed that one-third of cell phones were shared, and over one-half had received health-related messages for other people. Further, theft of cell phones and changing of cell numbers was common, and one-quarter of those living in rural areas were unable 
to keep their phone charged due to unreliable, inaccessible, or costly electricity. ${ }^{63}$

A range of issues must be resolved before m-health truly addresses the needs of the developing world, in particular vulnerable and poor or extremely poor groups. These include practical issues (means of "charging" cell phones - both power and connectivity; depth and breadth of coverage), more fundamental issues (poor technical and health literacy; confidentiality and privacy), and many other issues ("unsafe sharing", and regional, gender-related, and socioeconomic variations), as well as cost.

\section{Remote monitoring}

This area is poised for marked and innovative growth. The phrase "remote patient monitoring" will fade as uses for wellness influence future applications, and the simpler term "remote monitoring" is adopted and becomes the favored term. Two fundamental types of monitoring currently exist: external monitors and indwelling monitors. It has been suggested monitoring is common in our physical world, but not our personal world. For example, modern cars have hundreds of sensors, and even smart phones now have many, but humans are said to be "flying blind". From a physiological standpoint, this is incorrect (many sophisticated and sensitive sensors and feedback processes exist within the body), but the concept of accessing and broadcasting that data is absent. This will continue to change with indwelling monitors sending telemetry, allowing health care professionals to control the device and collect data, or external monitors of vital signs automatically collating and wirelessly transferring the data to health care providers when connectivity is available. These types of solutions will become more sophisticated and common, with initial markets being in developed countries (US, Canada, UK, Germany, France, Italy, Spain, Japan, People's Republic of China, Australia), but with growth in remote monitoring in India and Brazil, followed by other developing countries soon thereafter.

\section{"There's an App for that ...."}

An "app" (or application) is nothing more than a small, specialized program downloaded onto mobile devices. Numbers vary, and are changing daily, but there are more than 500,000 apps for i-Phones alone, many health- or medicinerelated. Currently an unregulated area of activity, greater standardization (and regulation) will transform apps from being quirky and novel to being essential and embedded into the health care delivery process, even in the developing world. Health care providers will maintain contact with and monitor their patients remotely through apps. Individuals will monitor their own well-being or chronic disease through a health dashboard on their mobile devices. Initially out of reach of most of the developing world population, steady inroads will be made through expanding utility for CHWs, and then introducing more modest apps for the general population. The number of apps will decrease and the quality increase as standards are developed to ensure well-designed and intuitive usability and functionality.

Potential applications are broad: Awareness building, appointment reminders, point-of-care support, point-of-care testing, point-of-care diagnostics, patient monitoring, disease and outbreak surveillance, emergency medical response, health information management, supply chain management, education, e-learning, and e-commerce, to suggest a few. Similarly, potential rewards are significant: Raising treatment compliance will improve outcomes; encouraging behavior change will improve self-care; surveillance will ensure timely intervention and reduce emergency or catastrophic care; and monitoring patient physiology with indwelling or peripheral sensors and monitors will identify issues before they become concerns.

\section{Making health fun!}

We know that many health problems are related to modifiable behavior. Changing behavior is difficult, and since when has anything to do with health care ever been fun? This will change through use of social media and related tools..$^{71,72}$ An area of opportunity still in its infancy in health care, but a multibillion-dollar business in the entertainment sector, is "gaming"; not in the sense of gambling or statistical reasoning, but in terms of social interaction and behavior change. Serious games and computer simulations (video games intended to be educational not just entertaining) appear to have potential to raise knowledge and understanding, and thereby change behavior. Vidal et $\mathrm{al}^{73}$ have developed "SimBody", an interactive simulator that educates people on how to mitigate the risk of cardiovascular diseases. The program provides lifestyle advice as well as showing the progression of atherosclerosis, and users have stated they intend to change their behavior and lifestyle. However, some note the paucity of sound theory, research, and evidence of impact and the danger of promoting, developing, or maintaining misconceptions that may have adverse consequences later in health care practice. ${ }^{74}$

\section{Training}

The urgent need to "build the capacity to build capacity" has been highlighted. ${ }^{41}$ Sufficient numbers of trained and 
well-supported health care providers are key to widening access to safe, quality health care services for the developing world. Often, CHWs are critical actors, providing surveillance, care, and education in rural and remote locations. Yet, CHWs in many settings work with minimal (or no) supervision, compensation, training, materials, or support. Telehealth applications could provide CHWs with the training and support they need.

In Ghana, Yusif and Soar identified 16 projects; most indicated the greatest need was education for health professionals (7/16) and many identified a lack of skills and human resources as limiting factors (6/16). ${ }^{75}$ Decentralization of training for health care personnel (in its various formats: Awareness; teaching; instruction; and education) to the community setting is viewed as positive. ${ }^{59}$ Community-based training facilitated through e-learning (telehealth) would enhance linkages between future HCWs and the population, provide rural populations with access to quality health care, give relevance to learning experiences, and raise awareness and use of telehealth.

\section{Discussion}

The beauty of telehealth is its ability to transgress the many barriers that mankind has erected-geographic, time, social, cultural, and political - giving it the "potential" to achieve health care support for "anyone, anytime, anywhere" (Byline of the former Canadian Society of Telehealth). This is also its major disadvantage. Such a vision conflicts with human behavior. Humankind creates artificial boundaries within which familiarity is maintained through written or unwritten guidelines or limitations and which establishes permissible behavior. Stepping outside those parameters creates uncertainty and discomfort. Why should attempts to fit something as global and diverse as telehealth into existing sovereign patterns of activity and practice be expected to succeed? Yet there is a profound need that success be achieved.

The developing world is home to about $80 \%$ of the world's population, many of whom live in abject poverty and dire need of health-related services - a stated "human right". The situation is compounded by the shortage of health care providers in rural and remote areas, by the absence of universal social public and primary health care, by the growing burden of noncommunicable diseases, by the lack of or inappropriately resourced rural health centers and hospitals, and by long distances and poor or nonexistent (and costly) transportation to urban health facilities. The low population density and distance factors are a disincentive for profitable commercial solutions (connectivity and service), and a significant task for resource-challenged government delivery of services. Telehealth is presumed to be a solution.

But telehealth, indeed any aspect of e-health, is not necessarily the best response. ${ }^{40}$ Optimal response to a problem must lie within the sphere of influence of the solution. Today's thought process is: e-health/telehealth is available - where can we use it? Tomorrow's thought process must become more pragmatic: what is the problem; what are possible solutions to that problem; might telehealth facilitate the optimal solution and help resolve the problem; if so, how is it successfully and sustainably designed, implemented, scaled, and integrated?

But even when selecting telehealth as a facilitator, conflicts arise. On the one hand, telehealth solutions should address what the "users" (eg, patients, health care providers) want. On the other hand, telehealth solutions should address evidence-based needs of the country, subnational region, or health care facility. The former approach raises the likelihood of buy-in, the latter approach raises the likelihood of sound investment and better population health. This dilemma will not be easily addressed.

Ideally, taking the time to interactively establish an evidence-based, needs-based, transparent, and defensible telehealth strategy (within an e-health strategy) would minimize conflict. ${ }^{22}$ Compromise is often the politic solution, investing primarily in the solutions derived from the evidence-based strategy with modest discretionary investment available for smaller focused applications.

\section{Conclusion}

The future of telehealth in the developing world is in our hands. The shortage of health workers and specialist services, and need for upgraded skills training remain the major problems and will continue to be so as the rate of health worker production fails to keep pace with population growth. Judicious use of telehealth offers a partial solution through direct clinical services (both intra- and interjurisdictional), training, and task shifting to lower levels of health workers. Achieving this at a national level requires political will, insight, coordination, and management of seemingly disparate factors. It must start with answering the population health and health system "needs", utilizing technologically appropriate and cost-effective solutions that are sensitive to the reality of the poverty of those most in need. Such an approach cannot be achieved through technological imperative or status quo approaches, but requires a structured approach through the development of synergistic e-health strategy (incorporating telehealth) at the national, 
subnational, and facility levels to guide public and private innovation, and broad user adoption.

\section{Disclosure}

The authors report no conflicts of interest in this work.

\section{References}

1. World Health Organisation. eHealth; 2014. Available from: http://www. who.int/topics/ehealth/en/. Accessed September 10, 2014.

2. Strehle EM, Shabde N. One hundred years of telemedicine: does this new technology have a place in paediatrics? Arch Dis Child. 2006;91(12):956-959.

3. Bashshur R, Shannon GW. History of telemedicine: evolution, context, and transformation. Healthc Inform Res. 2009;16:65-66.

4. Adera EO, Waema TM, May J, Mascarenhas O, Diga K. ICT Pathways to Poverty Reduction - Empirical Evidence from East and Southern Africa. Ottawa: Practical Action Publishing, IDRC; 2014.

5. ScottRE, Palacios MF. e-Health-challenges of going global. In: Scott CM, Thurston WE, editors. Collaboration in Context. Calgary: Institute for Gender Research and Health Promotion Research Group; 2003:9.

6. Fatehi F, Wootton R. Telemedicine, telehealth or e-health? A bibliometric analysis of the trends in the use of these terms. J Telemed Telecare. 2012;18(8):460-464.

7. Wootton R, Geissbuhler A, Jethwani K, et al. Long-running telemedicine networks delivering humanitarian services: experience, performance and scientific output. Bull World Health Organ. 2012;90(5):341D-347D.

8. Wootton R, Bonnardot L. In what circumstances is telemedicine appropriate in the developing world? JRSM Short Rep. 2010;1(5):37.

9. Eland-de Kok P, van Os-Medendorp H, Vergouwe-Meijer A, BruijnzeelKoomen C, Ros W. A systematic review of the effects of e-health on chronically ill patients. J Clin Nurs. 2011;20(21-22):2997-3010.

10. Mistry H. Systematic review of studies of the cost-effectiveness of telemedicine and telecare. Changes in the economic evidence over twenty years. J Telemed Telecare. 2012;18(1):1-6.

11. Bermo TS. Can economic evaluation in telemedicine be trusted? A systematic review of the literature. Cost Eff Resour Alloc. 2009; 7:18-27.

12. Pawson R, Greenhalgh T, Harvey G, Walshe K. Realist review - a new method of systematic review designed for complex policy interventions. J HealthServ Res Policy. 2005;10(Suppl 1):21-34.

13. Saul JE, Willis CD, Bitz J, Best A. A time-responsive tool for informing policy making: rapid realist review. Implement Sci. 2013;8(1):103.

14. World Health Organization. World Health Report 2006: Working Together for Health. Geneva: WHO Press; 2006:1-209.

15. OECD Health Statistics 2014. How does Canada compare?; 2014. Available from: http://www.oecd.org/els/health-systems/Briefing-NoteCANADA-2014.pdf. Accessed September 23, 2014.

16. Watson D, McGrail K. More doctors or better care? Healthc Policy. 2009;5(10):26-31.

17. World Health Organization. World Health Statistics 2014 - Global Health Indicators; 2014. Available from: http://www.who.int/gho/ publications/world_health_statistics/2014/en/.Accessed September 23, 2014.

18. Cooke R, Couper I, Versteeg M. Human resources for rural health. South African Health Rev. 2011:107-117.

19. Chanda KL, Shaw JG. The development of telehealth as a strategy to improve health care services in Zambia. Health Info Libr J. 2010;27(2): 133-139.

20. Mars M. Telehealth in sub-Saharan Africa. In: Wootton R, Patil NG, Scott RE, Ho K, editors. Telehealth in the Developing World. London: RSM Press; 2009:140-141.

21. Alwan A. Global Status Report on Noncommunicable Diseases 2010. Geneva: World Health Organization; 2011:2.

22. Scott RE, Mars M. Principles and framework for e-health strategy development. J Med Internet Res. 2013;15(7):e155.
23. BCC Research LLC. Global Markets for Telemedicine Technologies; Report Code: HLC014F; 2013. Available from: http://www.bccresearch. com/market-research/healthcare/telemedicine-technologies-hlc014f. html. Accessed September 23, 2014.

24. BCC Research LLC. Mobile Health (mHealth) Technologies and Global Markets. Report Code: HLC162A; 2014. Available from: http://www. bccresearch.com/market-research/healthcare/mobile-health-hlc162a. html. Accessed September 23, 2014.

25. Researchandmarkets. The Global Remote Patient Monitoring Market 2014 - 2018; 2014. Available from: http://www.researchandmarkets.com/reports/2785474/global_remote_patient_monitoring _ market_20142018. Accessed September 23, 2014.

26. Pan E, Cusack C, Hook J, et al. The value of provider-to-provider telehealth. Telemed J E Health. 2008;14(5):446-453.

27. Scott R, Mars M, Hebert M. How global is 'e-Health' and 'knowledge translation'? In: Ho K, Jarvis-Selinger S, Lauscher HN, Cordeiro J, Scott RE, editors. Technology Enabled Knowledge Translation for eHealth. New York: Springer; 2012:339-357.

28. Jahangirian M, Taylor SJ. Profiling e-health projects in Africa: trends and funding patterns. Inf Dev. 2013;8:0266666913511478.

29. Meso P, Mbarika VWA, Sood SP. An overview of potential factors for effective telemedicine transfer to Sub-Saharan Africa. IEEE Trans Inf Technol Biomed. 2009;13(5):734-739.

30. Durrani H, Khoja S. A systematic review of the use of telehealth in Asian countries. J Telemed Telecare. 2009;15(4):175-181.

31. Al-Shorbaji N. e-Health in the Eastern Mediterranean region: a decade of challenges and achievements. East Mediterr Health J. 2008;14: S157-S173.

32. Wootton R, Patil NG, Scott RE, Ho K, editors. Telehealth in the Developing World. London: RSM Press; 2009.

33. Lewis T, Synowiec C, Lagomarsino G, Schweitzer J. e-Health in lowand middle-income countries: findings from the Center for Health Market Innovations. Bull World Health Organ. 2012;90(5):332-340.

34. Zachariah R, Bienvenue B, Ayada L, et al. Practicing medicine without borders: tele-consultations and tele-mentoring for improving paediatric care in a conflict setting in Somalia? Trop Med Int Health. 2012;17(9): 1156-1162.

35. Nicogossian AE, Doarn CR. Armenia 1988 earthquake and telemedicine: lessons learned and forgotten. Telemed $J$ E Health. 2011;17(9):741-745.

36. Alkmim MB, Figueira RM, Marcolino MS, et al. Improving patient access to specialized health care: the telehealth network of Minas Gerais, Brazil. Bull World Health Organ. 2012;90(5):373-378.

37. Haddad AE, Alkmim MBM, Wen CL, Roschkes S. The implementation experience of the national telehealth program in Brazil. Global Telemed eHealth Updates. 2008;1:365-369.

38. Wootton R, Vladzymyrskyy A, Zolfo M, Bonnardot L. Experience with low-cost telemedicine in three different settings. Recommendations based on a proposed framework for network performance evaluation. Glob Health Action. 2011;4.

39. Wootton R, Geissbuhler A, Jethwani K, et al. Long-running telemedicine networks delivering humanitarian services: experience, performance and scientific output. Bull World Health Organ. 2012;90(5):341D-347D.

40. Mars M, Scott RE. Telemedicine service use: a new metric. J Med Internet Res. 2012;14(6):e178.

41. Mars M. Building the capacity to build capacity in e-health in subSaharan Africa: the KwaZulu-Natal experience. Telemed J E Health. 2012;18(1):32-37.

42. D'Agostino M, Al-Shorbaji N, Abbott P, et al. eHealth initiatives to transform health in the region of the Americas. Special Issue on eHealth in the Americas. Rev Panam Salud Publica. 2014;35(5/6): 326-328.

43. Li J. Building a healthy Malaysia; 2014. Available from: http:// www.futuregov.asia/articles/2010/jan/07/building-healthy-malaysia/. Accessed September 23, 2014.

44. Bashshur RL. Guest editorial: compelling issues in telemedicine. Telemed J E Health. 2013;19(5):330-332. 
45. Sharma SB. Telenursing - a potential resource in the ehealth agenda of India. J Int Soc Telemed eHealth. 2014;2(1):19-28.

46. Ganapathy K, Ravindra A. Telemedicine in India: the apollo story. Telemed J E Health. 2009;15(6):576-585.

47. Carroll M, Horton MB. Telehealth and Indian healthcare: moving to scale and sustainability. Telemed J E Health. 2013;19(5):377-379.

48. Zhao J, Zhang Z, Guo H, et al. e-Health in China: challenges, initial directions, and experience. Telemed J E Health. 2010;16(3): 344-349.

49. Chen J, Xia Z. Telemedicine in China: Opportunities and challenges. In: Wootton R, Patil NG, Scott RE, Ho K, editors. Telehealth in the Developing World. London: RSM Press; 2009:140-141.

50. Panir JH. Role of ICTs in the health sector in developing countries: a critical review of literature. J Health Inform Dev Ctries. 2011;5(1):12.

51. Mars M. Telemedicine and advances in urban and rural healthcare delivery in Africa. Prog Cardiovasc Dis. 2013;56(3):326-335.

52. Schuttner L, Sindano N, Theis M, et al. A mobile phone-based, community health worker program for referral, follow-up, and service outreach in rural Zambia: outcomes and overview. Telemed JE Health. 2014;20(8):721-728.

53. Källander K, Tibenderana JK, Akpogheneta OJ, et al. Mobile health (mHealth) approaches and lessons for increased performance and retention of community health workers in low-and middle-income countries: a review. J Med Internet Res. 2013;15(1):e17.

54. DeRenzi B, Findlater L, Payne J, et al. Improving community health worker performance through automated SMS: Proceedings of the Fifth International Conference on Information and Communication Technologies and Development. London, UK: ACM; 2012:25-34.

55. Tamrat T, Kachnowski S. Special delivery: an analysis of mHealth in maternal and newborn health programs and their outcomes around the world. Matern Child Health J. 2012;16(5):1092-1101.

56. Mechael PN. The case for mHealth in developing countries. Innovations. 2009;4(1):103-118.

57. Piette JD, Datwani H, Gaudioso S, et al. Hypertension management using mobile technology and home blood pressure monitoring: results of a randomized trial in two low/middle-income countries. Telemed $J$ E Health. 2012;18(8):613-620.

58. Gozzer E. How Peru and Latin America are using mHealth. Exch HIV/ AIDS Sex Gender. 2013;2:14-15.

59. Scott RE, Mars M. The spectrum of needed e-Health capacity buildingtowards a conceptual framework for e-Health 'training'. Stud Health Technol Inform. 2014;206:70-77.

60. Scott RE, Palacios M, Saeed A. Foundations in global e-health: a global capacity-building course. Stud Health Technol Inform. 2010;161: $122-131$.

61. United Nations. The Millennium Development Goals Report 2014; 2014. Available from: http://www.un.org/millenniumgoals/2014\%20 MDG\%20report/MDG\%202014\%20English\%20web.pdf. Accessed September 23, 2014
62. Sanou B. The World in 2013: ICT Facts and Figures. Geneva: International Telecommunications Union; 2013.

63. Jack CL, Mars M. Ethical considerations of mobile phone use by patients in KwaZulu-Natal: obstacles for mhealth? Afr J Prim Health Care Fam Med. 2014;6(1):7.

64. Horton R. GBD 2010: understanding disease, injury, and risk. Lancet. 2012;380(9859):2053-2054.

65. Lim SS, Vos T, Flaxman AD, et al. A comparative risk assessment of burden of disease and injury attributable to 67 risk factors and risk factor clusters in 21 regions, 1990 - 2010: a systematic analysis for the global burden of disease study 2010. Lancet. 2013;380(9859):2224-2260

66. GBD 2010 Country Collaboration. GBD 2010 country results: a global public good. Lancet. 2013;381(9871):965-970.

67. Al-Shorbaji N. Is there and do we need evidence on eHealth interventions? IRBM. 2013;34(1):24-27.

68. Motamarri S, Akter S, Ray P, Tseng CL. mHealth: a better alternative for healthcare in developing countries. Pacific Asia Conference on Information Systems (PACIS), Vietnam, AISeL; 2012.

69. Wesolowski A, Eagle N, Noor AM, Snow RW, Buckee CO. Heterogeneous mobile phone ownership and usage patterns in Kenya. PLoS One. 2012;7(4):e35319.

70. Blumenstock J, Eagle N. Mobile Divides: Gender, Socioeconomic Status, and Mobile Phone use in Rwanda. Proceedings of the 4th ACM/ IEEE International Conference on Information and Communication Technologies and Development. London, UK: ACM; 2010:6.

71. Ma M, Jain LC, Anderson P, editors. Future trends of virtual, augmented reality, and games for health. In: Ma M, Jain LC, Anderson P, editors. Virtual, Augmented Reality and Serious Games for Healthcare 1. Berlin, HD: Springer; 2014:1-6.

72. Grajales FJ 3rd, Sheps S, Ho K, Novak-Lauscher H, Eysenbach G. Social media: a review and tutorial of applications in medicine and health care. J Med Internet Res. 2014;16(2):e13.

73. Vidal B, Pereira JM, Santos G. SimBody: An Interactive Simulator for Health Education. In: Arnab S, Dunwell I, Debattista K, editors. Serious Games for Healthcare: Applications and Implications. Hershey, PA: IGI Global; 2013:345.

74. Garcia-Ruiz MA, Tashiro J, Kapralos B, Vargas Martin M. Crouching tangents, hidden danger: Assessing development of dangerous misconceptions within serious games for healthcare education. In: Hai-Jew S, editor. Virtual Immersive and 3D Learning Spaces: Emerging Technologies and Trends. Hershey: Information Science Reference; 2011:212.

75. Yusif S, Jeffrey SOAR. Preparedness for e-Health in developing countries: the case of Ghana. J Health Inform Dev Ctries. 2014;8(2):19.
Smart Homecare Technology and TeleHealth

\section{Publish your work in this journal}

Smart Homecare Technology and TeleHealth is an international, peer-reviewed, open access online journal publishing original research, reviews, editorials and commentaries on the application of technology to support people and patients at home and in assisted living centers to optimize healthcare and management resources. Specific topics in the journal include: Development and application of

\section{Dovepress}

devices within the home and embedded in appliances; Healthcare provider communication and education tools; and drug ordering and adherence. The manuscript management system is completely online and includes a very quick and fair peer-review system, which is all easy to use. Visit http://www.dovepress.com/ testimonials.php to read real quotes from published authors. 